\title{
Impact of core stability education on postural control in children with spastic cerebral palsy \\ Mostafa S. Ali
}

Department of Physical therapy for Pediatrics, Faculty of Physical therapy, Cairo University, Egypt

Correspondence to Mostafa S. Ali, Lecturer of Physical therapy for Pediatrics, Faculty of Physical therapy, Cairo university Egypt, 7 Ahmed Alzayate ST, Been Alsarayat, 12662 Giza. Tel: 01097720514;

e-mail: drmostafamalak9912@gmail.com

Received 31 October 2018

Accepted 25 March 2019

Bulletin of Faculty of Physical Therapy 2019, 24:85-89

\begin{abstract}
Background
Postural control includes controlling the body's position in space to achieve stability and orientation. Core stability education is applied to teach children to improve balance and postural control.
\end{abstract}

\section{Objective}

The objective of this study was to detect the impact of core stability education on postural control in children with spastic cerebral palsy (CP).

\section{Patients and methods}

Thirty spastic CP children (6-8 years) received intervention in the outpatient clinic of Faculty of Physical Therapy, Cairo University.

\section{Intervention}

The participants were randomly divided into a control group and a study group; the control group received selective therapeutic exercises, while the study group received the same selective program in addition to core stability exercises three times/week for 60 min for 12 weeks.

Main outcome measures

Dynamic balance was assessed by Biodex Balance System before and after treatment (12 weeks).

Results

There was a significant improvement of all stability indices (anteroposterior, mediolateral, and overall) in each group. There was more improvement in the study group when comparing post-treatment values of both groups $(P<0.05)$.

\section{Conclusion}

According to the results of the current study, core stability program is highly recommended to be included in the treatment program of spastic $\mathrm{CP}$ children to improve balance.

\section{Keywords:}

cerebral palsy, children, core stability education, postural control

Bulletin of Faculty of Physical Therapy 24:85-89

(C) 2019 Bulletin of Faculty of Physical Therapy

$1110-6611$

\section{Introduction}

Cerebral palsy (CP) could be a cluster of disorders that have an effect on the event of movement and posture, inflicting activity limitation, and nonprogressive disturbances that occurred within the developing fetal or child brain [1]. The main therapeutic goals for children with $\mathrm{CP}$ are the performance of functional activities and walking [2]. Children with $\mathrm{CP}$ have a limitation with activities due to the existing impairments in independent walking, climbing stairs, running, or walking over uneven surface [3]. Functional limitation of children with $\mathrm{CP}$ may have various degrees due to loss of axial control with an imbalance of their movements [4]. Balance has been defined as the elements of postural control that allow a child to safely perform everyday tasks [5]. Poor balance control is one of the most contributing factors for poor gait and reaching movement because the maintenance of stability is critical to all movements [6]. Children with $\mathrm{CP}$ have defects in postural mechanisms, including righting and equilibrium reactions, antigravity mechanism, proximal stability, and postural fixation [7]. Core stability is defined as the ability to maintain position and movement of body core. Stability training involves the abdomen muscles and pelvic and shoulder muscles, which maintain postural alignment and allow movements of extremities. Postural control is mainly for motion and depends on these muscles for stability and endurance [8]. Components of core stability include strength, endurance, balance, and the related activity of the back, abdominal, and pelvic muscles $[9,10]$. The core muscles act like one block to keep the body stable during static state and with extremity motion [11]. CP children lack the ability to distribute the load, that is, body weight, appropriately during static balance and transfer the body weight adequately from one

This is an open access journal, and articles are distributed under the terms of the Creative Commons Attribution-NonCommercial-ShareAlike 4.0 License, which allows others to remix, tweak, and build upon the work non-commercially, as long as appropriate credit is given and the new creations are licensed under the identical terms. 
supporting limb to another during dynamic balance tasks [12]. Children with diplegic $\mathrm{CP}$ are characterized by impairment of motor control in the lower extremities more than in the upper extremities. Moreover, hemiplegic children have motor disabilities of one half of the body; hence, they present with limited postural adjustment of the lower extremities in specific external disturbance [13].

\section{Patients and methods \\ Patients}

The current study included 30 children with mild spastic CP. Their ages ranged from 6 to 8 years (both sexes) and they did not receive core stability program before 6 months at least. The required height was $1 \mathrm{~m}$ and more. Their spasticity ranged from 1 to $1+$ according to the Modified Ashworth Scale [14]. The included children had to have normal flexibility of the lower back muscles, as adequate flexibility with normal muscle length is essential for proper joint function and efficient movement [15]. Children who were not following instructions were excluded from the study. In addition to children with any cardiopulmonary problems, those with attitude and psychiatric disorders, length discrepancy, and seizures were also excluded. Children with tightness of the hip flexors were also excluded from the sample, as, if the iliopsoas muscle is tight or shortened, this causes inhibition of the deep abdominals and gluteus maximus muscles, which leads to improper control of the back with more shear forces on the lower lumbar vertebrae [15].

\section{Study design randomized control trail Randomization}

Randomization was implemented simply by means of a computer-generated randomized table using the SPSS program (IBM, Armonk, New York, USA) that was prepared ahead of data collection. A specific identification number was assigned for each participant. These numbers were randomized into two groups. Individual and sequentially numbered index cards were secured in opaque envelopes. Each participant was given a hand-picked envelope and was relocated accordingly to their groups.

This randomized controlled trial was conducted from June 2017 to January 2018 at the outpatient clinic of Faculty of Physical Therapy, Cairo University in accordance with the Code of Ethics of the World Medical Association (Declaration of Helsinki) for experiments involving humans. Ethical committee approvals of the Faculty of Physical Therapy, Cairo
University, Egypt, and signed written consent form with parent acceptance for participation in the study and publication of the results was obtained before starting the procedure. The study aim and procedures were explained to their parents. They were divided into two equal groups (control and study). The control group received regular therapeutic exercise program. The study group received the same therapeutic exercise and core stability education program for 12 weeks. All children received education training for an hour three times/week for 12 weeks.

\section{Sample size}

The sample size was calculated by assuming the difference in the mean value of the change in overall stability index between the two groups, with an effect size of 1.1. Assuming $\alpha=0.05$ and power of $80 \%$, a sample size of 15 patients per group would be required (G Power 301; http://www.psycho.uni-duesseldorf. de). If further dropout of any child in this study occurred, it was replaced automatically ( $G$ Power 301; http://www.psycho.uni-duesseldorf.de).

\section{Procedures}

Biodex stability system is an important balance assessment and training system. In addition, it is a unique device that is designed to evaluate dynamic postural control and exercising method to improve balance and motion ability [14]. The aim is to investigate the impact of core stability program on postural control in children with spastic CP. Balance test was performed to investigate the child's ability to stabilize the angle of the tilting platform. Postural control was assessed before and after the intervention to determine which group was more affected, using The Biodex Balance System to measure overall stability index (anteroposterior stability index and mediolateral stability index). All participants were given instructions before conducting the test to perform the different test steps. Each child was asked to stand on the locked platform center with both legs in the stance phase. Hand rails and screen biofeedback were adjusted for each child to attain optimal safety and to look straight at it. The child was instructed to maintain position on the platform by moving his feet position while keeping the center of the platform in the center on the screen grid with the body in upright comfortable position. When the cursor was placed in the center of the screen, the command was given to the child to maintain position to control the tilting platform. Thereafter feet angles were recorded and the test began. After introducing angles into the 
device system, as the platform moved, the child was asked to lock on the screen and keep the cursor in the middle. At the end of each child test trial, the report was printed, which included measurable variables of stability indices. When high values of stability indices were attained, this implied that there were balance problems. This procedure was performed for each child at level 5 of both groups before and after 12 weeks.

\section{Intervention}

All children received a regular therapeutic exercise program (neurodevelopmental techniques, balance exercises, facilitation of milestones, and facilitation of postural reaction) for $1 \mathrm{~h} /$ day three times/week for 12 weeks, while the study group received core stability education program with three levels for 12 weeks, three times/week for $60 \mathrm{~min}$ in each session. The core stability education program included three levels. Each exercise takes $5 \mathrm{~min}$, and there is a shift from one exercise to the next after complete performance of the first. The first simple level included supine abdominal draw in (repeat 20 times), abdominal draw in with double knee to chest (repeat 10-20 times), and supine twist (repeat 10-20 times). The second medium level included pelvic bridging (three to five times) and twist with medicine ball (repeat 10-20 times). The third difficult level included bridging with head on physioball (hold this position for 3-5 s then slowly relax and repeat 10-20 times) and prone bridging (repeat entire sequence three to five times). These exercises have been used in previous studies to determine the effects of core stability exercises [16].

\section{Data analysis}

Results are expressed as mean \pm SD. Test of normality, the Kolmogorov-Smirnov test, was used to measure the distribution of data. Accordingly, comparison between normally distributed data in the two groups was performed using unpaired $t$ test. Comparison between pretreatment and post-treatment data within the same group was performed using paired $t$ test. Statistical package for social sciences computer program (version 19, Windows) was used for data analysis. $P$ value less than or equal to 0.05 was considered significant.

\section{Results}

There were no significant differences of the descriptive data (mean age, weight, and height) between both groups $(P \leq 0.05)$ (Table 1$)$ and also between both groups before conducting core stability education training. However, there was a high improvement in all measuring variables of control group before treatment and after treatment, wherein the percentage of improvement in the measured variables was $29.19,32.66$, and $19.85 \%$, respectively. In addition, there was a significant improvement in all stability indices of the study group before treatment and after treatment. The improvement percentage in the measured variables was $46.38,46.94$, and $41.23 \%$, respectively (Table 2 ), and the results revealed that there was a significant reduction in all measuring variables of the study group compared with the control group (Table 3).

\section{Discussion}

The purpose of the current study was to detect the effect of core stability education on postural control in children with spastic CP. The results of the current study revealed a significant reduction in all stability indices, which might improve by the effect of regular physiotherapy program and core stability program, but there was a significant improvement in postural control

Table 1 Descriptive data

\begin{tabular}{lcccc}
\hline & $\begin{array}{c}\text { Control group (mean } \\
\pm S D)\end{array}$ & $\begin{array}{c}\text { Study group } \\
(\text { mean } \pm S D)\end{array}$ & $\begin{array}{c}t \\
\text { value }\end{array}$ & $\begin{array}{c}P \\
\text { value }\end{array}$ \\
\hline Age & $6.98 \pm 0.33$ & $6.71 \pm 0.51$ & -0.13 & $0.87^{*}$ \\
Weight & $22.12 \pm 2.245$ & $22.9 \pm 2.32$ & -0.88 & $0.36^{*}$ \\
Height & $119.32 \pm 3.88$ & $118.41 \pm 6.6$ & 0.41 & $0.62^{*}$ \\
\hline
\end{tabular}

*Nonsignificant.

Table 2 The results of pretreatment and post-treatment in control and study groups

\begin{tabular}{lccccc}
\hline Stability indices & Before treatment $($ mean \pm SD $)$ & After treatment $($ mean \pm SD $)$ & \% of change & $t$ value & $P$ value \\
\hline Control group & & & & & \\
$\quad$ Anteroposterior & $2.49 \pm 0.27$ & $1.7 \pm 0.3$ & 29.19 & 8.49 & $0.0001^{* *}$ \\
$\quad$ Mediolateral & $2.38 \pm 0.40$ & $1.67 \pm 0.39$ & 32.66 & 5.25 & $0.0001^{* *}$ \\
$\quad$ Overall & $2.91 \pm 0.18$ & $2.40 \pm 0.47$ & 19.85 & 4.90 & $0.001^{* *}$ \\
Study group & & & & \\
$\quad$ Anteroposterior & $2.51 \pm 0.29$ & $1.30 \pm 0.25$ & 46.38 & 9.79 & $0.0001^{* *}$ \\
$\quad$ Mediolateral & $2.33 \pm 0.48$ & $1.20 \pm 0.26$ & 46.94 & 8.99 & $0.0001^{\text {** }}$ \\
$\quad$ Overall & $2.92 \pm 0.25$ & $1.71 \pm 0.38$ & 41.23 & 12.94 & $0.0001^{* *}$ \\
\hline
\end{tabular}

**Significant. 
Table 3 The results between post-treatment in control and study groups after 12 weeks

\begin{tabular}{lcccc}
\hline Stability indices & Control group & Study group & $t$ value & $P$ value \\
\hline After treatment & & & & \\
Anteroposterior & $1.7 \pm 0.3$ & $1.30 \pm 0.25$ & 4.48 & $0.0001^{\star *}$ \\
Mediolateral & $1.67 \pm 0.39$ & $1.20 \pm 0.26$ & 4.16 & $0.0001^{* *}$ \\
Overall & $2.40 \pm 0.47$ & $1.71 \pm 0.38$ & 2.63 & $0.01^{\star *}$ \\
\hline
\end{tabular}

${ }^{\star *}$ Significant.

in post-treatment scores of the study group after 12 weeks of treatment, as compared with the control group, which clarifies the effect of the core stability program. The prime factor for improvement of postural control in both the groups could be an improved trunk stability and postural alignment as a result of increased trunk muscle strength by conventional exercises $[17,18]$. Balance is correlated to trunk muscle strength [19]. The education of core stability education program encourages body control, which stimulates the feed-forward system to achieve postural activity of extremities. The co-ordination between the trunk and the upper extremities can be integrated by functional motions, which allow the body to move without regard to starting position in the available range of motion [20]. The improvement in trunk stabilization by performing core stability program led to (a) improved length tension relationship of the upper and lower limb muscles that originate from the girdles, which in turn are linked to the spine, (b) improved phasic contraction of spinal muscles, and (c) decreased freezing and improved degree of freedom, leading to smoother and more appropriate and purposeful movements [21]. Observation of pretreatment mean values of the current study confirms the findings of Chow et al. [22] who reported that both bilateral and coactivation of abdominals and back muscles are unavoidable during trunk movement, because they act as one block to gain balance between motion and fixation of the axial part. The results of the dynamic postural control test obtained from both groups with regard to the measuring variables revealed nonsignificant difference. An increase in their values indicates postural control problems that were consistent with Rose et al. [23] who concluded that the higher the stability indices, the more movements and the less stability during the test. The dynamic postural control may be explained by the study carried out by Carr and Shepherd [24] who reported that it was impaired in diplegic children because of relative imbalance between muscle agonists and antagonists across joints, equilibrium reactions disorders, and persistence of primitive reflex patterns for ambulation and muscle tone problems. The results came in agreement with the study by Niam and
Anderson [25] who explained that patients with spastic $\mathrm{CP}$ have incoordination within motor strategies, abnormal muscle tone and movement control, postural imbalance, and loss of superficial and deep sensation that lead to loss of static and dynamic balance. The study group received a specially designed program for core stability, as core muscles are important for $\mathrm{CP}$ children to move in and out of the standing position. This follows the study results of Dodd and colleagues who reported that core muscles stabilize the central part of the body to allow controlled movements of the upper limbs and lower limbs. Thus, a core stability program may be modified to enhance postural control and balance for $\mathrm{CP}$ children [26]. The exercise of bridging causes all back muscles to contribute in a similar way to control spine positions and movements in a healthy population [27]. Veerle et al. [17] have supported the above-mentioned view by studying the relative muscle activity and the ratios of the back muscles in three bridging exercises (single bridging, ball bridge, and unilateral bridging), demonstrating similar activity levels for all back muscles, resulting in ratios about [1]. The results of the current study were reinforced by Gillen, who concluded that children with spastic $\mathrm{CP}$ have a defect with the timing gain motor response to support surface perturbations like delayed muscle activation onset, which moves the center of the mass towards the limit of stability and leads to more proximal muscles' activation before distal muscles, when responding to support surface perturbations in standing, which is the opposite to that found in a child with normal control. Finally, children with spasticity have been found to have postural adjustment deficit associated with voluntary control in static and dynamic activities [28]. The improvement in post-treatment values for both groups in all measured variables was achieved through activation of abdominal and back muscles in various exercises to reach optimal muscle strength. This was consistent with Park et al. [29] who explained that better Sitting posture improved due to strength of back and abdominal muscle at the same time. Moreover, the results might be caused by postural control improvement from different patterns. This agreed with Harbourne et al. [30] who concluded that postural control improves dynamic balance. 
There was a significant improvement in postural control in post-treatment scores of the study group after 3 months of treatment, as compared with the control group, which clarifies the effect of core stability education program applied to the study group. This was consistent with the outcome of the study by Cowley and Swensen, [10] who reported that core stabilization training improves dynamic balance in mentally retarded students. Improvement of balance in the study group might be explained by Sterba et al. [31] who reported that trunk and pelvic strengthening exercises will improve postural and equilibrium reactions in children with $\mathrm{CP}$. Postural control and reciprocal co-ordination of the lower extremities to achieve equilibrium during dynamic activities occurred in the study group with regard to core stability education program; these results came in agreement with Visintin et al. [32] who explained the effect of strengthening exercises of the trunk (core stability training) on dynamic balance and postural control in diplegic children.

\section{Study limitations}

(1) The number of children in each group was small.

(2) Postural control test was performed on Biodex Balance System for one trial only.

\section{Conclusion}

It can be concluded that core stability education program is a good strategy to solve postural control and balance deficits in children with spastic CP.

\section{Financial support and sponsorship}

Nil.

\section{Conflicts of interest}

There are no conflicts of interest.

\section{References}

1 Bax M, Goldstein M, Rosenbaum P, Leviton A, Paneth N, Dan B, et al. Proposed definition and classification of cerebral palsy, April 2005. Dev Med Child Neurol 2005; 47:571-576.

2 Shepherd R. Cerebral palsy. In: Shepherd R, ed. Physiotherapy in pediatrics. Oxford: Butterworth-Heinemann 1995. 110-144

3 Styer-Acevedo J. Physical therapy for the child with cerebral palsy. In: Jan S. Tecklin. Pediatric physical therapy. 3rd ed. Philadelphia, PA: Lippincott Williams \& Wilkins 1999.

4 Seymour R. Prosthetics and orthotics: lower limb and spine. Philadelphia PA: Lippincott Williams \& Wilkins 2002. 367-426

5 Koman LA, Smith BP, Shilt JS. Cerebral palsy. Lancet 2004; 363:1619-1631.

6 Shumway-Cook A, Woollacott MH. Motor control. theory and practical application. 2nd ed. Philadelphia, PA: J. B. Lippincott 2001.
7 Wade L, Canning C, Fowler K, Flemingham K, Baguley I. Changes in postural sway and performance of functional tasks during rehabilitation after traumatic brain injury. Arch Phys Med Rehabil 1997; 78:1107-1111.

8 Briggs A, Greig A, Wark J, Fazzalari N, Bennell K. A review of anatomical and mechanical factors affecting vertebral body integrity. Int $\mathrm{J}$ Med Sci 2004; 1:170-180

9 Liemohn WP, Baumgartner TA, Gagnon LH. Measuring core stability. J Strength Cond Res 2005; 19:583-586.

10 Cowley P, Swensen T. Development and reliability of two core stability field tests. J Strength Cond Res 2008; 22:619-624.

11 Zazulak B, Hewett T, Reeves N, Goldberg B, Cholewicki J. The effects of core proprioception on knee injuries: a prospective biomechanical epidemiological study. Am J Sports Med 2007; 35:368-373.

12 Wiley ME, Damiano DL. Lower-extremity strength profiles in spastic cerebral palsy. Dev Med Child Neurol 1998; 40:100-107.

13 Ju Y, Hwang I, Cherng R. Postural adjustment of children with spastic diplegic cerebral palsy during seated hand reaching in different directions, Arch Phys Med Rehabil 2012; 93:471-479.

14 Bohannon RW, Smith MB. Inter-reliability of modified ashworth scale of muscle spasticity. Phy Ther 1987; 67:206-207.

15 Fredericson M, Moore T. Muscular balance, core stability, and injury prevention for middle- and long-distance runners. Phys Med Rehabil Clin N Am 2005; 16:669-689.

16 Lahatinen $U$, Rintala $P$, Malin A. Physical performance of individuals with intellectual disability: a 30-year follow up. Adapt Phys Activ Q2007; 14:125-143.

17 Veerle KS, Andry V, Katie GB, Nele NM, Guy GV, Lieven AD. Electromyographic activity of trunk and hip muscles during stabilization exercises in four-point kneeling in healthy volunteers. Eur Spine J 2007; 16:711-718.

18 Bobath K. A neurophysiological basis for the treatment of cerebral palsy. London: Spastics International Medical Publications: William Heinemann Medical Books; Philadelphia : Lippincott; 1980

19 Ayres AJ. Sensory integration and learning disorders. Los Angeles: Western Psychological Service; 1972.

20 Gracies J, Burke K, Clegg N, Browne R, Rushing C, Fehlings D, Delgado MR. Reliability of the tardieu scale for assessing spasticity in children with cerebral palsy. Arch Phys Med Rehabil 2010; 91:421-428.

21 Unayik M, Kahiyan H. Down syndrome: sensory integeration, vestibular stimulation and neurodevelopmental therapy approaches for children?. In Stone $\mathrm{JH}$, Blouin $\mathrm{M}$ eds. International encyclopedia of rehabilitation. Turkey: The Center for International Rehabilitation Research Information and Exchange (CIRRIE) 2011.

22 Chow JW, Shim JH, Lim YT. Lower trunk muscle activity during the tennis serves. J Sci Med Sport 2003; 6:512-518.

23 Rose J, Wolff DR, Jones VK, Bloch DA, Oehlert JW, Gamble JG. Postural balance in children with cerebral palsy. Dev Med Child Neurol 2011; 44:58-63.

24 Carr, Shepherd R. Physical therapy in pediatrics. 3rd ed. Heinemann, Oxford: Butter Worth 2011. 51-53

25 Niam S, Anderson W. Balance and physical impairments after stroke. Arch Phys Med Rehabil 2010; 80:1227-1233.

26 Saggini R, Vecchiet J, lezzi S, Racciatti D, Affaitati G, Bellomo RG, Pizzigallo E. Submaximal aerobic exercise with mechanical vibrations improves the functional status of patients with chronic fatigue syndrome. Eura Medicophys 2006; 42:97-102.

27 Dodd K, Taylor N, Damiano D. Systemic review of strengthening for individuals with cerebral palsy. Arch Phys Med Rehabil 2012; 83:1157-1164.

28 Gillen G. Trunk control: a prerequisite for functional independence: a function based approach. St Louis: Mosby 2013. 69-89

29 Park E, Park C, Lee H, Cho Y. The effect of electrical stimulation of the trunk control in young children with spastic diplegic cerebral palsy. J Korean Med Sci 2001; 16:347-350.

30 Hartbourne R, Willett S, Kyvelidou A, Deffeyes J, Stergiou N. A comparison of interventions for children with cerebral palsy to improve sitting postural control: a clinical trial. Phys Ther 2010; 90:1881-1889.

31 Sterba J, Rogers B, France A, Vokes D. Horseback riding in children with cerebral palsy, effect on gross motor function. Dev Med Child Neurol 2002; 8:301.

32 Visintin M, Chakrabarty S, Martin J. The effect of body weight support on the locomotor pattern of spastic paretic patients. Can J Neuro Sci 1989; 16:315-325. 